\title{
Revisión sistemática: los antihipertensivos mejoran el pronóstico materno en la hipertensión inducida por el embarazo
}

Fortnightly review: management of hypertension in pregnancy. Magee LA, Ornstein MP, von Dadelszen P. BMJ 1999;318:1332-1336.

\section{Objetivo}

Revisar los estudios controlados aleatorizados de tratamientos no farmacológicos y con drogas para el tratamiento de la hipertensión arterial (HTA) en el embarazo.

\section{Origen de los datos}

Se buscó en Medline (1966-97), bibliografía y textos de estudios relevantes y artículos de revisión sobre HTA en el embarazo.

\section{Estudios seleccionados}

Estudios controlados y aleatorizados en inglés o francés que reunieran determinados criterios: intervención no farmacológica (incluyendo reposo en cama y admisión en un hospital) o farmacológica, y resultados clínicos dirigidos a observar beneficios o riesgos maternos, perinatales o pediátricos.

\section{Resultados principales}

Se detectaron mejorías en distintos marcadores de morbilidad
(HTA grave, internaciones, proteinuria en el parto o distress respiratorio), aunque no hubo cambios en la mortalidad perinatal tanto en HTA crónica leve (siete ensayos clínicos aleatorizados) como en HTA inducida por el embarazo. La elección del antihipertensivo no tuvo importancia. Para las mujeres con HTA temprana en el embarazo, el tratamiento agresivo aumentó el riesgo de morbilidad neonatal, la internación en sectores de cuidados especiales neonatológicos, la enterocolitis necrotizante, y el síndrome de distress respiratorio. Por otra parte, el tratamiento disminuyó el riesgo de tener un recién nacido de bajo peso para la edad gestacional. La hidralazina endovenosa se asoció con mayor HTA materna, mayor número de cesáreas y apgar menores que con otros agentes, y mas bradicardia neonatal que con labetalol.

\section{Conclusión}

El tratamiento farmacológico de la HTA crónica leve o inducida por el embarazo mejora el pronóstico materno, pero no es claro el efecto sobre el pronóstico fetal.

Fuente de financiameinto: no referida.

\section{Comentario}

Si bien podría hipotetizarse cierto sesgo de selección en la población incluida en este estudio de meta-análisis, parece claro que la mujer embarazada con HTA crónica leve a moderada, tolera bien la medicación antihipertensiva y se beneficia con ella disminuyendo la incidencia de HTA grave, la necesidad de utilizar antihipertensivos adicionales y la presencia de proteinuria en el parto 1,2 . Sin embargo, no queda claro cuando iniciar el tratamiento antihipertensivo. Si se va a iniciar tratamiento farmacológico se prefiere no utilizar atenolol hasta que haya mayor evidencia que lo avale. Los resultados comunicados no permiten sacar conclusiones confiables acerca de los riesgos y beneficios de restringir la actividad física con o sin internación en las pacientes con HTA leve al final de la gestación.

Por otra parte no son claros los beneficios del tratamiento antihipertensivo para el feto, excepto cuando se presenta una preeclampsia con HTA aguda y grave antes de la semana 34 de gestación, momento en el que se prefiere adoptar una conducta expectante en lugar de un tratamiento agresivo 3,4

\section{Dr. Gabriel Waisman [ Unidad de Fisiología Clínica e Hipertensión Arterial. Servicio de Clínica Médica. Hospital Italiano de Buenos Aires ]}

\section{Referencias}

1. Sibai BM. Treatment of hypertension in pregnant women. N Engl J Med 1996; 335:257-65.

2. Steyn DW, Odendaal HJ. Randomised controlled trial of ketanserin and aspirin in prevention of pre-eclampsia. Lancet 1997; 350:1267-71.

3. Sibai BM, Mercer BM, Schiff E, Friedman SA. Aggressive versus expectant management of severe preeclampsia at 28 to 32 weeks'gestation: a randomized controlled trial. Am J Obstet Gynecol 1994;171:818-22.

4. Odendaal HJ, Pattinson RC, Bam R, Grove D, Kotze TJ. Aggressive or expectant management for patients with severe preeclampsia between 28-34 weeks'gestation:a randomized controlled trial.Obstet Gynecol 1990;76:1070-5

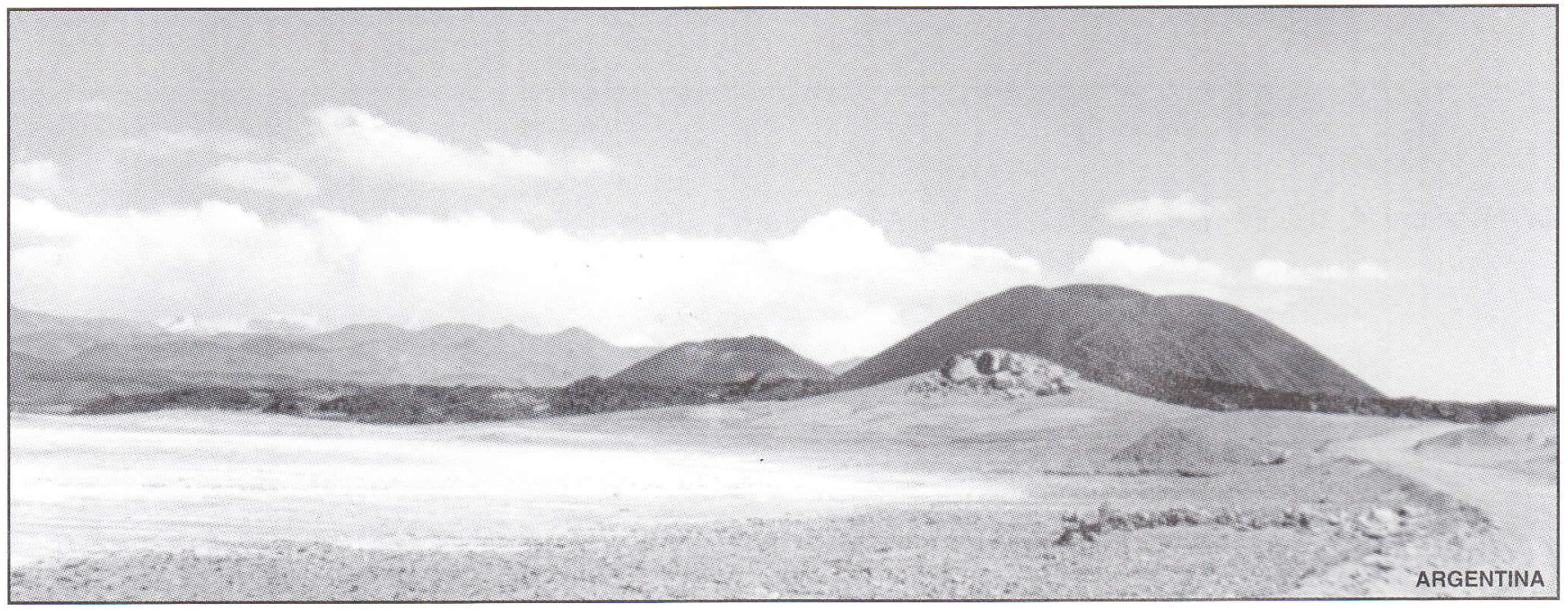

